\title{
STRUCTURE OF SUSTAINABLE ECONOMIC VALUE IN SOCIAL ENTREPRENEURIAL ENTERPRISES
}

\author{
Tom G. Strothotte and Rolf Wüstenhagen
}

\section{INTRODUCTION}

Social Entrepreneurial Enterprises (SEEs) are companies that are founded with the mission to change the world in a specific socially oriented way rather than to provide an (economic) ROI (Bornstein, 2004). The social mission is usually accomplished incrementally by convincing other members of society of their cause. The degree to which the social mission is accomplished is the function which an SEE tries to optimize while at the same time remaining economically viable and independent. As SEEs are entrepreneurial enterprises, they are associated with a high risk of failure, yet at the same time they empower their leaders through independence.

The activities of SEEs are often financed by manpower that is generously given free of charge by individuals who are convinced of the social mission. The only cash flows available are generally from charitable contributions. In rare cases, these are augmented by government grants. Some SEEs eventually provide themselves with cash flows by selling products related to their businesses. For example, the World Wildlife Fund (WWF), albeit no longer an entrepreneurial enterprise, funds part of its socially minded activities through the sale of its own line of cuddly animals, and it remains true to its mission by selling replicas only of such animals as are threatened by extinction.

The Emergence of Entrepreneurial Economics Research on Technological Innovation, Management and Policy, Volume 9, 129-140

Copyright (C) 2005 by Elsevier Ltd.

All rights of reproduction in any form reserved ISSN: 0737-1071/doi:10.1016/S0737-1071(05)09008-6 
Financing of SEEs is always a problem, since an SEE can usually do better at achieving its social mission with cash than without. In this chapter, we will demonstrate that indeed SEEs, under certain circumstances, can produce economic value added and can convert this into a stream of cash flows which can be used to fund the SEE. However, such income is not without its problems, since social entrepreneurs often do not want to see themselves 'making money', but emphasis instead their role in 'changing the world'. Even if they are willing to endeavour in activities to produce income to fund their SEE, the places in which economic value added is generated are often overlooked. This chapter deems to close this gap.

The chapter is organized as follows. Section 2 discusses the sustainability of SEEs by first setting up requirements for the social mission of an SEE. It is shown that only if this mission is sustainable can the SEE itself be sustainable. Next, Section 3 outlines where economic value added is generated in an SEE. A 'customer value' approach is taken to examine the activities of an SEE and to derive where the value is harboured. The latent nature of such value is not uncommon in the 'customer value' approach, and Section 4 then turns to methods of converting such value added into a stream of cash flows. Finally, concluding remarks and suggestions for future work are given in Section 5.

\section{SUSTAINABILITY}

Most authors nowadays use the notion of sustainability in the sense of Brundtland (1987), which proposes that "sustainable development is development that meets the needs of the present without compromising the needs of future generations to meet their own needs". Corporate Sustainability has also been conceptualized as a triple-bottom line (Elkington, 1998), i.e., simultaneous creation of economic, environmental and social value. While much research has been done to operationalize environmental sustainability (Wackernagel \& Rees, 1996; Schönwandt, 2004; Hockerts, 2003a, b), the concepts of economic and social sustainability and their interrelationships are relatively less well researched (Emerson, 2000, 2003). We look at these aspects in our chapter, with a particular focus on the activities of SEEs. At the outset, we shall analyse the circumstances under which an SEE is in itself 'sustainable' in the original sense of the word, i.e., long-term viable. This in turn has implications for its financing. We propose the notion of the sustainability of a (social) mission and suggest that an SEE is only sustainable if its mission is sustainable. 


\subsection{Sustainability of a Mission}

We can observe that once a company's raison d'être vanishes, it will cease to exist. While a company whose goal is to generate economic value can, in principle, go on operating indefinitely, an SEE must be analysed to see if it too can do so. The raison d'etre of an SEE is its (social) mission, and once this is accomplished the SEE ceases to exist. We say that an SEE with a mission, which can be accomplished in an overseeable amount of time, has an unsustainable mission, while an SEE whose mission will probably never be accomplished, or at least not for a long time, has a sustainable mission. Examples of unsustainable missions are:

(1) Abolish the production of products using polyvinylchloride (PVC) all over the world (this mission was eventually accomplished).

(2) Achieve a high market penetration of green freezer technology in Germany (this mission was also accomplished).

It should be noted that once a mission is accomplished, a new mission may be to monitor that the mission actually remains accomplished and backlashes do not occur. Also accomplishing a mission to $100 \%$ may be exorbitantly expensive, whereas a lower degree of accomplishment (e.g., $90 \%$ ) may be much less expensive. Hence, a trade-off between the degree of accomplishment of a mission and the cost will have to be considered.

Examples of sustainable missions in the sense outlined above are:

(1) To raise awareness of human rights violations by governments. The reason why this is sustainable is that there will probably always be governments that will violate human rights - in particular since the definition of human rights is not generally agreed upon and may change over time.

(2) To save all animal species existing today from extinction. The problem is so large and diverse that it probably cannot ever be solved, hence the mission is sustainable.

(3) Provide each child in the developing world with a sponsor in the developed world. This is a goal which is unattainable in the foreseeable future, hence the mission is sustainable.

It is useful to treat the sustainability of a social mission as a continuum depending on the length of time or the amount of resources necessary to accomplish the mission. This continuum will then be divided into 'low sustainability' and 'high sustainability'. We shall use these notions later on in this chapter. 


\subsection{Economic Sustainability}

Economic sustainability should be the goal of any enterprise, including SEEs, even though in their case the social mission has the higher priority. We refer to economic sustainability as a state in which an enterprise can pay for its own activities through its income, i.e., has a viable business plan. This goal will have a lower priority for an SEE than for a regular commercial venture, and indeed those involved in an SEE may not see nor want to achieve economic sustainability.

Fig. 1 shows the relationship between economic sustainability and sustainability of the social mission. Note that if the SEE's mission is not sustainable, a change or exit strategy must be devised so as to cover the situation that arises when the mission is accomplished or - in the worst case - if it cannot be accomplished. In the situation that the SEE produces low economic value added, also an exit strategy or a change strategy must be developed so as either to provide funding for the SEE through new economic value added, or a change strategy which adjusts the mission or business plan to make the SEE sustainable.

Pertaining to Fig. 1, horizontal transitions come about as a result of a change in social mission. The transition may also come about as a result of

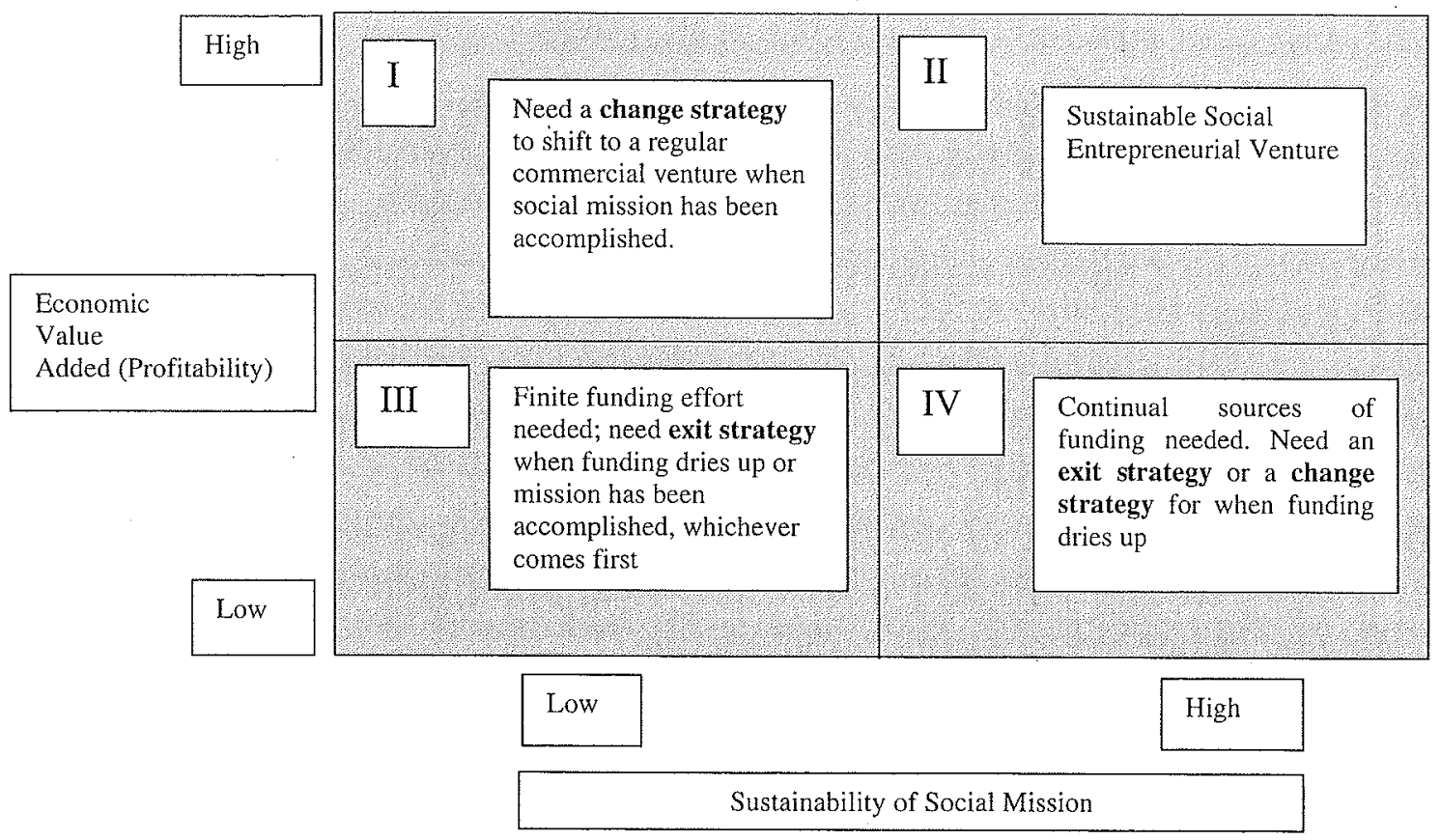

Fig. 1. Relationship between Economic Value Added and Sustainability of the Mission for SEEs. 
the SEE's environment changing, i.e., the sustainability of the mission changes in its perception in either direction.

Vertical transitions come about as a result of changes in the success of the implementation of the business model or as a result of changes in the business model itself.

\subsection{Sustainability of SEES}

We shall now turn to SEEs based on the definition of SEEs and their dichotomy given above. According to the dichotomy of the missions of SEEs there will be differences in the SEEs depending on the sustainability of the mission upon which they are based. The other factor which influences the sustainability is the economic viability as an enterprise.

(1) SEEs based on sustainable missions are sustainable SEEs if they have an adequate business plan; and

(2) SEEs based on unsustainable missions are unsustainable SEEs.

We shall study such SEEs in turn.

An example of a company which was unsustainable - we conjecture due to the unsustainability of its mission - is Foron Haus- und Kühltechnik $\mathrm{GmbH}$, which was active in East Germany in the early 1990s (Hockerts, 2004). This company started as an SEE whose mission was to change the world in the sense of convincing people to use a specific greener technology for freezers. This is an unsustainable mission because eventually other freezer producers will cffer and push green freezers. By choosing the method of producing, marketing and sell such freezers it positioned itself in QIV. It completed its mission when the other freezer makers decided to get into this market, too; the business moved into QI/QIII. At this point, all that was left was an entrepreneurial enterprise with a poor business plan that was doomed to failure. Eventually, it became evident that it had landed in QIII and ultimately went bankrupt.

Consider the society Hochbegabte e.V. (Berlin) as an example of a sustainable SEE. This society has as its mission to make a contribution to the education of gifted children. Such children have an intelligence quotient (IQ) of over 140 (representing about $2 \%$ of the population) and often cause problems in school because they are bored. The mission is sustainable because there is a constant supply of new gifted children, and because public policy in Germany is unlikely to change quickly enough for the state to handle the education of these children by itself. 


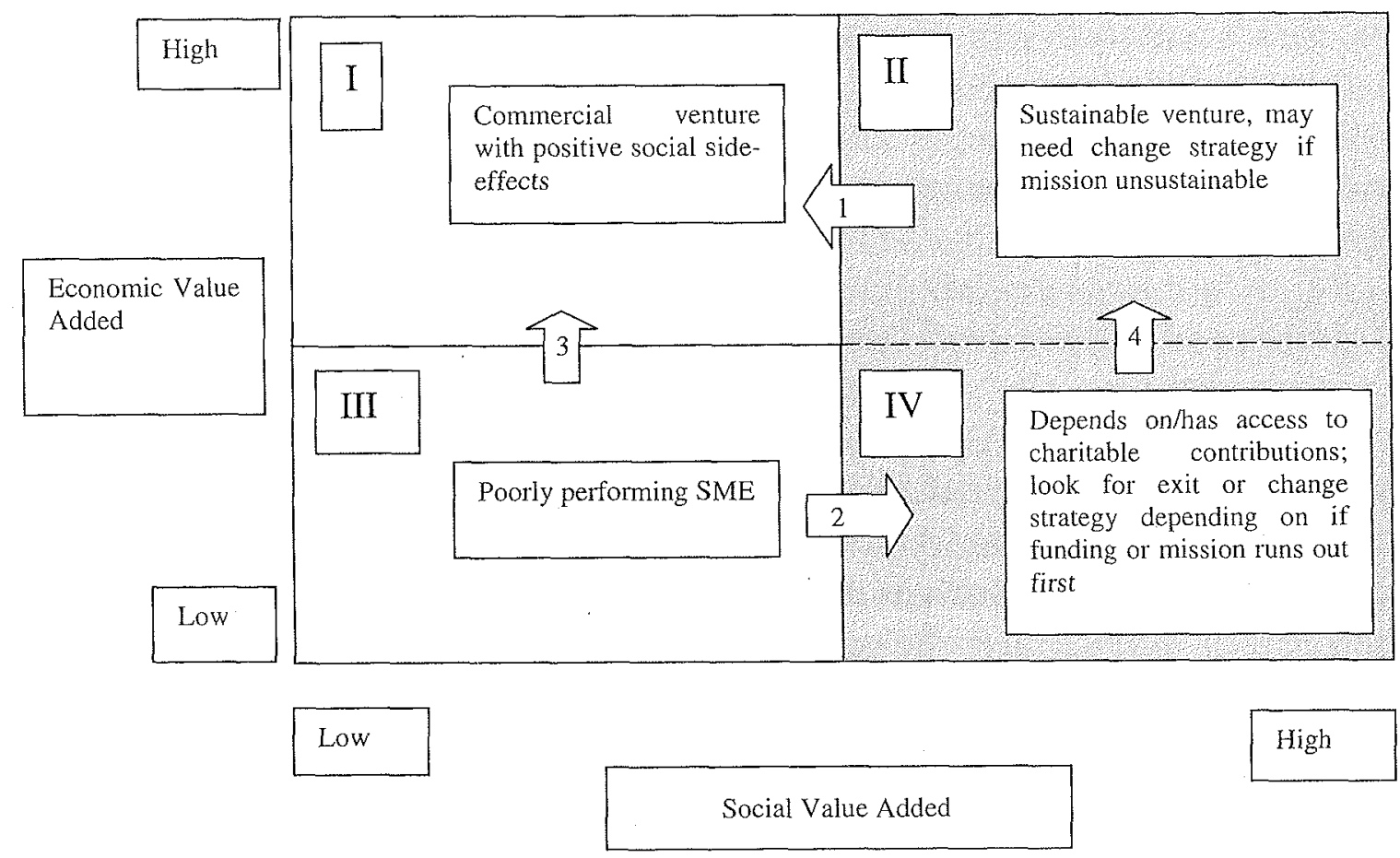

Fig. 2. Relationship between Economic Value Added and Social Value Added. Companies used on the Right Half of the Diagram are SEEs. Some of the Transitions between Quadrants can be Explained with Respect to the Sustainability of the Social Mission on which the SEE is Based.

Fig. 2 now summarizes the situation of SEEs with respect to the fulfilment of the social mission (referred to as 'social value added') and their economic value added (as their ability to fund themselves).

Note that any SEE will be somewhere on the plane of Fig. 2. The primary goal will be to be as far to the right as possible; however, the higher up the better, as this gives the SEE income to continue its work.

Some of the transitions between quadrants of Fig. 2 are of interest in the present context.

(1) QII to QI (decreasing social value added at a high level of economic value added, arrow No. 1): In this transition, a successful SEE changes into a commercial venture. This is a necessary transition if the mission is unsustainable (Foron $\mathrm{GmbH}$ after the other freezer makers entered the market). The transition is also made in the case that the mission is sustainable, but the leaders of the firm are losing their social touch (for whatever reason). This transition may require an exit strategy for the initiators of the SEE because they may not want to work for a purely commercial venture. 
(2) QIII to QIV (increasing social value added at a low level of economic value added, arrow No. 2): In this transition, a poorly running commercial venture takes on a social mission in order to get access to charitable contributions (perhaps as a way to survive). This can only be a stop-gap measure, as ventures in QIV may not last very long in their own right. An example is a software company offering image-processing software which is not doing well and tries to save itself by beginning to adapt its software for use by blind computer users, even though the number of clients is too small to yield a viable business case.

(3) QIII to QI (increasing economic value added at a low level of social value added, arrow No. 3): Such a transition is the job of management consultants (they may, as a side effect, position the company even lower on the social value added scale).

(4) QIV to QII (increasing economic value added at a high level of social value added, arrow No. 4): The SEE is implementing a change strategy, having discovered how to fund its social mission. For instance, the WWF going into the business of selling stuffed animals. This makes particular sense for SEEs with sustainable social missions, but can also apply to ones with unsustainable missions.

Having looked at the sustainability of SEEs, we can see the need for sustainability both with respect to the mission as well as the economic value added. Hence, in the next section, we will turn to a method of identifying the economic value added by an SEE and how this can be used to fund the SEE itself.

\section{ECONOMIC VALUE OF SEES: A CUSTOMER VALUE PERSPECTIVE}

Having examined the relationship between economic value added and social value added, we are now in a position to take a step further and ask the question where this economic value is harboured. The background to this question is twofold: Ultimately, we will want to try to convert this economic value added into cash flows which can be harvested. While the previous section pointed to difficulties with this approach, we consider it to be a necessary step on the way to realizing the social mission set out for the SEE. Indeed, we will turn to this topic in the next section. In the meantime, the current section will assess the structure of this economic value. 
Our approach to determining where the economic value added is harboured is based on the notion of customer value (Belz \& Bieger, 2004). Underlying this approach is the assumption that a company can increase its shareholder value (thus its economic value) by focusing on increasing the value of its products and services for its customers. The logic of this approach makes use of a value chain as follows: (1) Creating customer value leads to (2) increased cash flows on the part of the customer. These cash flows can be viewed as (3) an increase in customer equity. Thereby increasing the (4) customer portfolio value. This in turn increases the (5) shareholder value of the company offering the product or service.

Two important challenges lie on this chain. On the one hand, customer value created by the company providing the product or service must actually lead to increased cash flows on the part of the customer. For example, if a service is provided more quickly, this must be turned into an economic benefit. Second, part of the enhanced cash flows must flow back to the company providing the product or service. Otherwise, economic value may actually be destroyed because providing the customer value is often associated with increased costs. To stay with the example, to provide a product or service more quickly presumably increases the costs to the company providing this product or service; at least this amount must be recovered from the customer for it to be a worthwhile proposition.

In this section, we shall concentrate on the first element on this chain, i.e., identifying how an SEE enhances customer value. How to convert this customer value into economic value for the SEE will then be the topic of Section 4.

\subsection{An SEE's Customers}

First, we must define who the customer of an SEE really is, taking into account the peculiarities of SEEs. We note that SEEs may not have customers in the traditional sense of someone who pays a market price for a product or a service. Instead, recall that an SEE's primary goal is to achieve a social mission rather than to create economic value. Hence, for the analysis, it is appropriate to choose a wider definition of the term 'customer' encompassing all persons or companies with direct or indirect contact with the SEE. ${ }^{1}$ Among these are persons and companies who

(1) use products or services of the SEE,

(2) influence the decisions of the aforementioned with respect to the products or services of the SEE or its social mission, 
(3) are potential users of the products or services, and

(4) are the SEE's suppliers and their own staff (including honorary workers).

Indeed, each customer can be seen as an SEE's chance to take an incremental step towards achieving its social mission.

\subsection{An SEE's Customer Value}

We are now in a position to identify a number of areas where an SEE's customer's value may be harboured. At the outset, it is important to note that the value which we are searching for is, for the present instance, generated implicitly in the course of the SEE's work towards achieving its social mission and is not cultivated explicitly. Hence, this customer value ought to be compatible with any social entrepreneur's social mission - indeed, we shall contend that it may not even be possible to generate some of this economic value, even if were not desired. But we shall return to this point later on in Section 4.

One area in which an SEE generates economic value is in the way its activities carry out an inherent market segmentation. For example, the customers of an enterprise promoting green energy will have certain attributes in common with a much higher probability than a random sample of the same size taken from the general population. These customers may, for example, also drive or be interested in driving cars which use fuel very efficiently; they may be interested in other products which are environmentally preferable, hence opening up cross-marketing opportunities.

An SEE such as alluded to must find people ('customers') who are susceptible to the notion of green energy as a first step towards promoting its use. This process of identifying its (potential) customers is otherwise called market segmentation. It costs money to segment a market appropriately and to find customers. Once these customers have been identified, their identity has a certain economic value assuming that someone is willing to pay for their identity.

Another aspect of customer value created by SEEs lies in the social status of actually being a customer. For example, persons donating money for a particular cause (as for the tsunami victims in Asia early in 2005) may receive decals which can be displayed for others to see. Another example was the movement against violence toward foreigners in which persons supporting this cause wore buttons with texts such as "Ne touche pas à mon pot". 
The point in time at which someone becomes a customer of an SEE may also have an inherent social status associated with it. Some social missions develop as bandwagons and it is no longer a distinction to be a customer. However, it may still be a distinction to belong to the first few customers who 'discovered' the SEE. For example, to have a small membership number in a society with many members may have some inherent value.

Yet another aspect of social status of being a customer arises when it is a particular privilege to be a customer. This situation comes up when certain prerequisites have to be fulfilled before one can become a customer. For example, one cannot simply become a member of a Rotary Club; membership is attained only by nomination from within the club and is restricted to highly recognized members of the community. An example of an SEE in this regard is Hochbegabten e.V., a society for the advancement of highly intelligent persons. In order to become a member of this society, proof must be provided that the prospective member's intelligence quotient (IQ) is at least 140 . Membership in such clubs or societies thus implies social prestige.

Finally, customers of SEEs often get to know one another through their activities related to the SEE. This contributes to the personal network of each customer - a network which can be leveraged for other purposes and thus has an inherent value.

\section{FROM CUSTOMER VALUE TO CASH FLOWS}

As indicated at the outset of the previous section, one of the particular challenges of the 'customer value' approach to creating economic value is that it is effective only if it is possible to actually create cash flows for the SEE. This is the point where social entrepreneurs or even their customers may be alienated because they believe in the non-profit nature of their mission. While it is important not to alienate these stakeholders, it is a reality that most SEEs can make better progress toward fulfilling their mission with free cash flows than without. Hence, the sources of economic value alluded to in the previous section should be taken seriously.

Nonetheless there remains the question how an SEE's customer value can be converted into cash flows, assuming that this is desired.

Table 1 provides a rather generic list of possible sources of economic value added. Of course, in each specific situation, an SEE should be analysed with the goal of identifying other such possible sources and devising methods of converting them into cash flows. 
Table 1. How to Realize Economic Value Added of SEEs.

\begin{tabular}{|c|c|}
\hline Type of Economic Value Added & How to Realize the Economic Value Added \\
\hline Market segmentation & $\begin{array}{l}\text { Provide visibility of other companies interested in this } \\
\text { market segment }\end{array}$ \\
\hline Social status of being a customer & $\begin{array}{l}\text { One-time and annual membership fees appropriate to } \\
\text { social status }\end{array}$ \\
\hline $\begin{array}{l}\text { Social status of being an early } \\
\text { customer }\end{array}$ & Exclusive special events (with fees) for such customers \\
\hline \multicolumn{2}{|l|}{ Limited customer base } \\
\hline Network among customers & $\begin{array}{l}\text { Maintain registry of customers (members) and charge } \\
\text { a fee for access to it }\end{array}$ \\
\hline
\end{tabular}

\section{CONCLUDING REMARKS}

In this chapter, we have outlined a method of systematically identifying possible sources of economic value added in social entrepreneurial enterprises. The method is based on the sustainability of the social mission, which is the basis of the SEE's activities.

In the chapter, we have assumed that the economic value added, which is to be converted into cash flows is generated as a by-product of the SEE's activities. It would be interesting to investigate whether or how this value can be developed systematically so as to provide more income for the SEE. This would move an SEE from being a strictly non-profit organization into one which also has commercial interests - even though these will likely be used exclusively to further the SEE's social mission.

While commercial activities by SEEs may be seen as a necessity on the part of a professional manager, they face resistance on the part of social entrepreneurs who carry out their activities on the basis of idealism. Ways of convincing them that their goals are best served by generating capital, which can be used to further their cause, will have to be developed in the future to provide a basis for an improvement of the funding situation of SEEs.

\section{NOTES}

1. We could also refer to this group as the SEE's stakeholders. 


\section{REFERENCES}

Belz, C., \& Bieger, T. (2004). Customer value-Kundenvorteile schaffen Unternehmensvorteile. Thexis, St Gallen.

Bornstein, D. (2004). How to change the world. Social entrepreneurs and the power of new ideas. Oxford.

Brundtland, G. (Ed.). (1987). Our common future: The World Commission on Environment and Development. Oxford.

Elkington, J. (1998). Cannibals with forks: The triple bottom line of the 21st century. Oxford.

Emerson, J. (2000). The nature of returns: A social capital markets inquiry into elements of investment and the blended value proposition. Harvard Business School working paper. www.blendedvalue.org

Emerson, J. (2003). The blended value proposition: Integrating social \& financial returns. California Management Review, (Summer), 35-51.

Hockerts, K. (2003a). Sustainability innovations, ecological and social entrepreneurship and the management of antagonistic assets. Ph.D. thesis, University of St Gallen, St Gallen.

Hockerts, K. (2003b). Case study: Mobility car sharing - from ecopreneurial start up to commercial venture. Winner of the 1st Oikos Sustainability Case Writing Competition. http://www.oikos-stiftung.unisg.ch/homepage/case.htm

Hockerts, K. (2004). Bootstrapping social change - towards an evolutionary theory of social entrepreneurship. Academy of Management Review, submitted.

Schönwandt, C. (2004). Sustainable entrepreneurship im sektor erneuerbare energien. Munich, Mering. Ph.D. thesis, University of Kassel.

Wackernagel, M., \& Rees, M. (1996). Our ecological footprint. New catalyst bioregional ser. (Vol. 9). Gabriola Island, BC: New Society Publishers. 